\title{
Possible association between acetazolamide administration during pregnancy and multiple congenital malformations
}

This article was published in the following Dove Press journal:

Drug Design, Development and Therapy

I5 April 2016

Number of times this article has been viewed

\author{
Afnan I Al-Saleem' \\ Asma M Al-Jobair ${ }^{2}$ \\ 'Dental Department, Prince Sultan \\ Military Medical City, Riyadh, Saudi \\ Arabia; ${ }^{2}$ Department of Pediatric \\ Dentistry and Orthodontics, College \\ of Dentistry, King Saud University, \\ Riyadh, Saudi Arabia
}

\begin{abstract}
Congenital malformations might occur because of environmental or genetic factors, and sometimes occur because of unknown causes. Acetazolamide is a carbonic anhydrase inhibitor that is used to treat idiopathic intracranial hypertension, glaucoma, and epilepsy. The use of acetazolamide has not been recommended for pregnant women because of reported teratogenic risks. Congenital malformations, such as ectrodactyly, syndactyly, cleft lip/palate, and retarded incisor teeth development, have been reported in experimental animals. However, tooth agenesis due to the use of acetazolamide has not been reported yet. Oligodontia is a severe type of tooth agenesis involving six or more congenitally missing teeth. The causes of oligodontia are attributed to environmental factors, such as irradiation, drugs, trauma, tumors, infection, genetic factors, or a combination. There is no credible evidence of undesirable effects of acetazolamide use in human pregnancy. However, we report a case of a 12-year-old Saudi boy who was exposed to maternal acetazolamide $(1,000 \mathrm{mg} /$ day $)$ for treatment of idiopathic intracranial hypertension before pregnancy, during the first trimester, and throughout the pregnancy. This treatment might have resulted in some congenital malformations, such as ectrodactyly, syndactyly, and oligodontia.
\end{abstract}

Keywords: acetazolamide, oligodontia, ectrodactyly, syndactyly

\section{Introduction}

Congenital malformations or birth defects are abnormalities that are present at or before birth and may involve several organs, including the heart, brain, liver, lungs, limbs, bones, intestinal tract, and others. ${ }^{1}$ The causes of congenital malformations can be classified into three categories of environmental, genetic, and unknown causes. A considerable percentage of congenital malformations of an unknown cause is likely to have environmental and genetic components. ${ }^{2}$ Environmental factors may include maternal conditions (eg, smoking, diabetes, and nutritional deficits), infectious agents (eg, rubella and syphilis), mechanical problems (eg, amniotic band constrictions and umbilical cord constraint), chemicals, prescription drugs, and high-dose ionizing radiation. ${ }^{2}$ These factors are considered as teratogenic agents that can alter fetal morphology or subsequent function with fetal exposure. The risk and type of malformations caused by teratogenic agents frequently result in a variety of malformations that differ depending on many factors. These factors include embryonic stage, exposure dose, threshold dose, pharmacokinetics, metabolism of the drug or the chemical, placental transport, and maternal/fetal genetic differences. ${ }^{2}$

Acetazolamide is a carbonic anhydrase inhibitor that is used to treat idiopathic intracranial hypertension (IIH), glaucoma, and some forms of epilepsy and is used as a diuretic. ${ }^{3}$ The use of acetazolamide is not recommended for pregnant women because of the reported teratogenic risks. Congenital malformations, such as ectrodactyly,
Correspondence: Asma M Al-Jobair Department of Pediatric Dentistry and Orthodontics, College of Dentistry, King Saud University, PO Box 60169, Riyadh

II545, Saudi Arabia

Tel +966 II 4676648

Email aaljobair@ksu.edu.sa
Drug Design, Development and Therapy 2016:10 |47|-1476

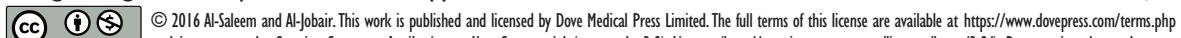
cc) hereby accept the Terms. Non-commercial uses of the work are permitted without any further permission from Dove Medical Press Limited, provided the work is properly atributed. For permision

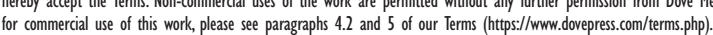

Dovepress

http://dx.doi.org/10.2147/DDDT.S9956 
syndactyly, a reduction in skeletal ossification, axial skeletal malformation, exencephaly, anophthalmia, microphthalmia, cleft lip/palate, and retarded incisor teeth development, have been reported in experimental animals. ${ }^{4-9}$ However, to the best of our knowledge, multiple tooth agenesis due to acetazolamide has not been reported yet.

The term tooth agenesis refers to the absence of one tooth or more. Oligodontia is a severe type of tooth agenesis involving six or more congenitally missing teeth, excluding the third molars. ${ }^{10,11}$ Oligodontia is a rare condition with a prevalence ranging from $0.03 \%$ to $0.14 \% .^{12-14}$ The causes of oligodontia are attributed to environmental factors, such as tumors, irradiation, drugs, trauma, infection, hereditary genetic factors, or a combination. ${ }^{15}$

There are no convincing data of undesirable effects of acetazolamide use in human pregnancy outcomes. ${ }^{16,17}$ However, we experienced a patient who was exposed to maternal acetazolamide before pregnancy, during the first trimester, and throughout the pregnancy. This might have resulted in some congenital malformations, such as ectrodactyly, syndactyly, and oligodontia.

\section{Case report}

A 12-year-old Saudi boy visited Pediatric Dentistry Clinics, Riyadh Dental Center, Riyadh Medical Complex in Riyadh, Saudi Arabia. He was then followed-up at Pediatric Dentistry Clinics, College of Dentistry, King Saud University in Riyadh, Saudi Arabia. Ethical approval from a review board was not necessary for this report, as all patients treated at the College of Dentistry, King Saud University, sign written informed consent for the use of their records for educational purposes. As the patient discussed in this report was underage, written informed consent was obtained from the father to publish this case. The patient complained of severe spontaneous pain on the lower side of his mouth for 3 days. He had previously visited a dentist for fillings and extractions. $\mathrm{He}$ is the fourth among five siblings. The boy presented with multiple congenital malformations (Figure 1). He presented
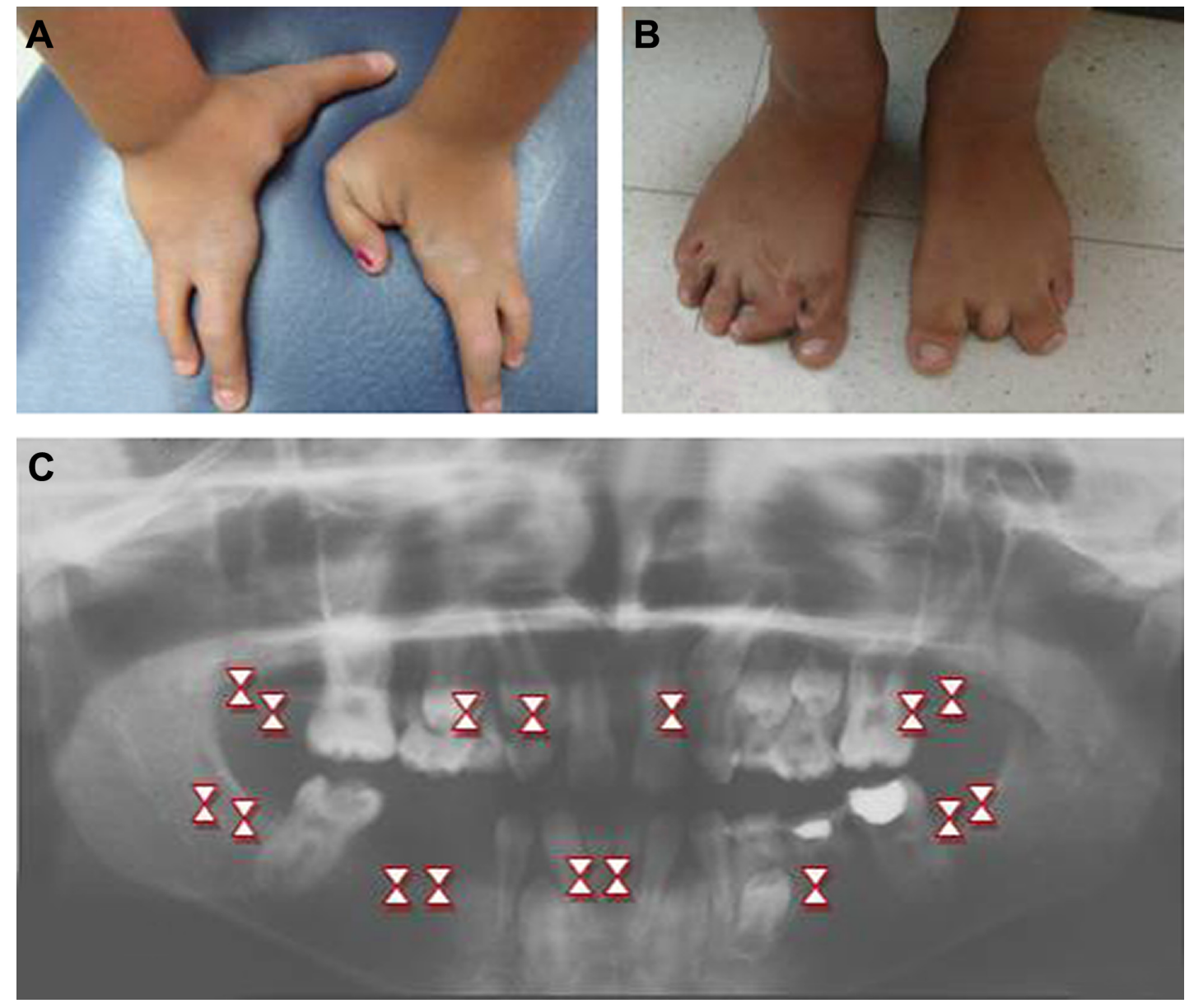

Figure I Congenital malformations associated with the reported case.

Notes: (A) Ectrodactyly of the index and middle fingers in both hands. (B) Syndactyly between the third and fourth toes of the left foot, in addition to ectrodactyly of the second toe and a deformed second toe of the right foot with a surgical scar. (C) Panoramic view shows oligodontia of 16 permanent teeth, as indicated by the triangular symbols. 
with ectrodactyly of the index and middle fingers in both hands (Figure 1A). There was syndactyly between the third and fourth toes of his left foot, in addition to ectrodactyly of the second toe. The second toe of the right foot was deformed with a surgical scar (Figure 1B). His parents are not related and there was no history of a similar familial condition.

The patient's mother had a history of acetazolamide treatment for a long time (no specific dose or exact period was mentioned). She previously had five spontaneous abortions, all of which were in the first trimester of pregnancy. Before the mother became pregnant with our patient, she was under acetazolamide treatment $(1,000 \mathrm{mg} /$ day $)$ for the treatment of IIH. As reported by the mother, she continued taking the same medication during the first trimester of pregnancy until the end of pregnancy, under the supervision of her physician. Additionally, she was taking folic acid. She had a full-term pregnancy, and a boy was delivered by spontaneous vaginal delivery without complications. The neonate was born with bilateral missing fingers and toes. He was $48.5 \mathrm{~cm}$ tall and weighed 2,270 g. At birth, he was tentatively diagnosed with ectrodactyly ectodermal dysplasia cleft palate syndrome (EEC syndrome). She also reported that she was lactating for 1.5 years while she was under acetazolamide treatment. She then became pregnant with the fifth child and was advised by her physician to stop acetazolamide. She delivered a normal neonate.

The 12-year-old boy presented to the pediatric dental clinics without major dysmorphic features. He was intelligent with good behavior. Skin, hair, and nails were normal. An intraoral examination showed that the patient had mixed dentition with retained primary lower central incisors, hypocalcified permanent upper incisors, and multiple carious teeth. The tongue, floor of the mouth, upper lip, and hard and soft palate were normal. A panoramic radiograph examination showed oligodontia of 16 permanent teeth (Figure 1C). According to the mother, nobody had noticed the missing teeth before this visit.

The boy was then referred to the genetic clinic in Riyadh Medical Complex to exclude any genetic disorders. A skeletal survey, chromosomal study, abdominal ultrasound, and cardiology evaluation were requested by the genetic consultant. All of the investigations were normal. Our patient was diagnosed by the genetic consultant as having isolated ectrodactyly, which was unlikely to be inherited, and there was a possibility of a teratogenic cause. All of the dental procedures were performed according to the treatment plan.

\section{Discussion}

We experienced a case of oligodontia, with a severe type of tooth agenesis involving 16 permanent teeth, in addition to congenital malformations of associated limbs, namely, ectrodactyly and syndactyly. Our first impression of the presence of oligodontia with other malformations besides the maternal history was that it was part of a genetic syndrome or teratogenic syndrome.

Dental anomalies can result from various factors, including environmental and genetic factors. Etiological events in the prenatal and postnatal periods can cause anomalies in the number, morphology, dimension, structure, and position of teeth. However, defects in certain genes result in the highest incidence of problems with teeth. ${ }^{18,19}$

Primary tooth formation and development usually begins at approximately the 6 th week in utero. However, permanent dentition begins to form at approximately the 14th week in utero, and mineralization is usually completed by $2-3$ years after teeth eruption. ${ }^{20}$ Odontogenesis, the process of tooth development, is an unstable process and can easily be disturbed and disrupted as a result of different factors. There are many reports of prenatal and postnatal administration of anticonvulsants, antibiotics, and chemotherapeutic drugs that have an adverse effect on teeth and oral tissues. ${ }^{21-24}$ The severity of tooth-related abnormalities, including tooth agenesis, secondary to drugs are related to the age of the child, dosage, and duration of the treatment. ${ }^{25}$ In our case, primary dentition was reported as complete by the mother and no one had discovered the hypodontia. The permanent dentition is more susceptible to disturbance by drugs and environmental toxicants than the primary dentition. ${ }^{26}$ Genetic hypodontia appears as an isolated feature or as part of a syndrome. Genes, such as $\operatorname{Pax} 9, M s x 1$, and Axin2, are involved in nonsyndromic hypodontia, while Pitx2, Shh, Irf6, and $p 63$ are considered to contribute to genetic syndromes. ${ }^{27,28}$

Embryonic limb development occurs during weeks 4 through 8 after conception. Digital rays begin to appear in the hand and foot during week 7. Absence of the central rays results in a congenital limb malformation known as ectrodactyly..$^{29}$ Ectrodactyly may occur as an isolated entity or as part of a syndrome. However, ectrodactyly is frequently observed in combination with other congenital anomalies. Such ectrodactyly syndromes may be caused by exposure of the embryo to environmental or genetic factors. Syndromes in which ectrodactyly is associated with other abnormalities may be the result of single gene defects or can occur when two or more genes are affected by chromosomal rearrangement. ${ }^{29}$ The most recognized human ectrodactyly syndrome is EEC syndrome, which was identified by Rüdiger et al in 1970. ${ }^{30}$ EEC is a complex multiple congenital anomaly/dysplasia syndrome that is characterized by ectrodactyly, ectodermal 
dysplasia, and cleft lip/palate in which any one of these main signs is present in variable expression. EEC is caused by mutations in the TP63 gene. ${ }^{31}$ The present case was diagnosed clinically at birth as EEC syndrome. However, neither cleft lip nor cleft palate was present. Additionally, no dysmorphic feature of ectodermal dysplasia was noticed. According to the mother, no other abnormality in different parts of the body was recognized. Nevertheless, variations in the expression of this syndrome still exist.

Acetazolamide is the basis of medical therapy for $\mathrm{IIH} .{ }^{17}$ The two major therapeutic goals in pregnant patients with IIH are to alleviate pain and to prevent vision loss because severe loss of vision develops in $10 \%$ of pregnant women with IIH. ${ }^{32}$ The therapeutic effects of acetazolamide are derived from inhibition of carbonic anhydrase, an enzyme that catalyzes (reversibly) hydration of carbon dioxide, and dehydration of bicarbonate. ${ }^{33}$ Maternal administration of acetazolamide in rodents results in a highly specific limb malformation in the offspring. Metabolic and respiratory acidosis have been linked to acetazolamide-induced ectrodactyly. ${ }^{34,35}$ Acetazolamide exerts its teratogenic action through induction of an acidotic embryonic environment. ${ }^{35}$

According to the US Food and Drug Administration, acetazolamide is classified as a class $\mathrm{C}$ drug. ${ }^{36}$ This indicates that animal reproduction studies have shown an adverse effect of acetazolamide on the fetus, but there are no well-controlled studies in humans. As a class C drug, acetazolamide should be prescribed only if the potential benefit justifies the potential risk to the fetus, according to US Food and Drug Administration recommendations. ${ }^{36}$ Acetazolamide is considered as category + , which means that it is generally compatible with breastfeeding.

In humans, sacrococcygeal teratoma, metabolic acidosis, hypocalcemia, and hypomagnesemia have been reported in newborns born to mothers under acetazolamide treatment. ${ }^{37,38}$ However, these reported cases showed little clinical evidence to support any adverse effect of this drug on pregnancy outcomes in humans. Lee et $\mathrm{al}^{16}$ and Falardeau et $\mathrm{al}^{17}$ reported that the risk of spontaneous abortion was similar in the treated and control groups, and there were no major complications in the newborns of women who were treated with acetazolamide. Although these studies do not prove that acetazolamide is safe during pregnancy, and negative data do not exclude the teratogenic possibility, they proposed that birth defects from acetazolamide, if they occur, are rare. Additionally, they suggested if the clinical situation mandates the use of acetazolamide in pregnant women with IIH, then this drug can probably be offered after proper informed consent.
However, these previous studies reported that the follow-up interval for their cases and those in the literature was relatively short, and late effects may have been missed. ${ }^{16,17}$ In our case, ectrodactyly and syndactyly were discovered at birth. However, oligodontia of the permanent teeth was not discovered until the patient was 12 years old. Oligodontia of permanent dentition might be considered as one of the late effects of acetazolamide that could be missed. Although tooth agenesis has not been reported, even in animal studies, Kojima et $\mathrm{al}^{8}$ postulated that maternal acetazolamide treatment causes retardation of incisor teeth development, which is partially independent of suppression of fetal weight. Our patient weighed 2,270 g at birth, which is below the fifth percentile. Maternal acetazolamide treatment suppresses fetal weight, as reported in many animal studies. ${ }^{4,8}$

When the patient visited us for the first time, we thought that this case was related to a genetic or teratogenic syndrome. However, after studying our patient and reviewing the literature, we believe that a combination of a genetic and teratogenic syndrome was involved. The huge complexity of the genome and its variety within populations, as well as in individuals, appear to be the major reason why the same teratogenic exposure can provoke severe malformation in one fetus, while it fails to do so to another exposed fetus. Variation in pregnancy outcomes of mothers who are treated with acetazolamide or other drugs indicates that embryonic genetic factors consisting of incalculable genetic mutations/variants, present within every individual, contribute to vulnerability to birth defects. ${ }^{1}$ Additionally, environmental factors comprise not only the biological, physical, and chemical external environment of the pregnant woman but also include the internal environment of the pregnant woman's body that interacts with the developing embryo in a multifaceted fashion. ${ }^{1}$

In this case report, we are not able to confirm the relation between reported clinical malformations and acetazolamide. This report aims to describe what we found extra- and intraorally and discuss these findings in light of the available literature. Detailed genetic analysis should be performed, and more animal studies should be conducted to determine the effect of acetazolamide on tooth agenesis. Regardless of the cause of oligodontia, it should not be ignored. Oligodontia may result in a variety of disturbances, such as abnormal occlusion, difficulty in speech and mastication, and altered facial appearance. Treatment not only improves speech and mastication but it also has a psychological impact that may be extremely helpful in retrieval of self-assurance. In this reported case, the patient received the required dental treatment, including extraction, root canal treatment, and 
multiple restorations. Further, removable partial dentures as an intermediate step before implants and fixed prostheses were also constructed. Until more definitive data are available, verifying the absence of pregnancy before initiation of acetazolamide would be prudent, and proper analysis should occur regarding the risk-benefit ratio of treatment.

\section{Disclosure}

The authors report no conflicts of interest in this work.

\section{References}

1. Wlodarczyk BJ, Palacios AM, Chapa CJ, Zhu H, George TM, Finnell RH. Genetic basis of susceptibility to teratogen induced birth defects. Am J Med Genet C Semin Med Genet. 2011;157C(3):215-226.

2. Brent RL. Environmental causes of human congenital malformations: the pediatrician's role in dealing with these complex clinical problems caused by a multiplicity of environmental and genetic factors. Pediatrics. 2004;113(4 Suppl):957-968.

3. Use of Acetazolamide in Pregnancy [webpage on the Internet]. UK Teratology Information Service; 2016. Available from: http:// www.medicinesinpregnancy.org/bumps/monographs/USE-OFACETAZOLAMIDE-IN-PREGNANCY/. Accessed March 29, 2016

4. Tellone CI, Baldwin JK, Sofia RD. Teratogenic activity in the mouse after oral administration of acetazolamide. Drug Chem Toxicol. 1980; 3(1):83-98.

5. Scott WJ Jr, Lane PD, Randall JL, Schreiner CM. Malformations in nonlimb structures induced by acetazolamide and other inhibitors of carbonic anhydrase. Ann N Y Acad Sci. 1984;429:447-456.

6. Beck SL, Urbano CM. Potentiating effect of caffeine on the teratogenicity of acetazolamide in C57BL/6J mice. Teratology. 1991;44(3): 241-250.

7. Biddle FG. Genetic differences in the frequency of acetazolamideinduced ectrodactyly in the mouse exhibit directional dominance of relative embryonic resistance. Teratology. 1988;37(4):375-388.

8. Kojima N, Naya M, Makita T. Effects of maternal acetazolamide treatment on body weights and incisor development of the fetal rat. $J$ Vet Med Sci. 1990;61(2):143-147.

9. Dodo T, Uchida K, Hirose T, et al. Increases in discontinuous rib cartilage and fused carpal bone in rat fetuses exposed to the teratogens, busulfan, acetazolamide, vitamin A, and ketoconazole. Hum Exp Toxicol. 2010;29(6):439-450.

10. Shimizu T, Maeda T. Prevalence and genetic basis of tooth agenesis. Jpn Dent Sci Rev. 2009;45:52-58.

11. Wang J, Jian F, Chen J, et al. Sequence analysis of PAX9, MSX1 and AXIN2 genes in a Chinese oligodontia family. Arch Oral Biol. 2011; 56(10):1027-1034.

12. Rølling S, Poulsen S. Oligodontia in Danish schoolchildren. Acta Odontol Scand. 2011;59(2):111-112.

13. Celikoglu M,KazanciF, Miloglu O, OztekO, Kamak H, Ceylan I. Frequency and characteristics of tooth agenesis among an orthodontic patient population. Med Oral Patol Oral Cir Bucal. 2010;15(5):e797-e801.

14. Aktan AM, Kara IM, Sener I, Bereket C, Ay S, Çiftçi ME. Radiographic study of tooth agenesis in the Turkish population. Oral Radiol. 2010;26(2):95-100.

15. Kapadia H, Mues GD, D'Souza R. Genes affecting tooth morphogenesis. Orthod Craniofac Res. 2007;10(4):237-244.

16. Lee AG, Pless M, Falardeau J, Capozzoli T, Wall M, Kardon RH. The use of acetazolamide in idiopathic intracranial hypertension during pregnancy. Am J Ophthalmol. 2005;139(5):855-859.

17. Falardeau J, Lobb BM, Golden S, Maxfield SD, Tanne E. The use of acetazolamide during pregnancy in intracranial hypertension patients. J Neuroophthalmol. 2013;33(1):9-12.
18. Basdra EK, Kiokpasoglou M, Stellzig A. The Class II Division 2 craniofacial type is associated with numerous congenital tooth anomalies. Eur J Orthod. 2000;22(5):529-535.

19. Uslu O, Akcam MO, Evirgen S, Cebeci I. Prevalence of dental anomalies in various malocclusions. Am J Orthod Dentofacial Orthop. 2009;135(3):328-335.

20. Cobourne MT, Dibiase AT. Development of the dentition. In: Handbook of orthodontics. 1st ed. Elsevier Health Sciences UK; 2010:86-105.

21. Grossman ER, Waichak A, Freedman H. Tetracyclines and permanent teeth: the relation between the dose and tooth color. Pediatrics. 1971; 47(3):567-570.

22. Orup HI Jr, Keith DA, Holmes LB. Prenatal anticonvulsant drug exposure: teratogenic effect on the dentition. J Craniofac Genet Dev Biol. 1998;18(3):129-137.

23. Alpaslan G, Alpaslan C, Gögen H, Oğuz A, Cetiner S, Karadeniz C. Disturbances in oral and dental structures in patients with pediatric lymphoma after chemotherapy: a preliminary report. Oral Surg Oral Med Oral Pathol Oral Radiol Endod. 1999;87(3):317-321.

24. Jacobsen PE, Henriksen TB, Haubek D, Østergaard JR. Prenatal exposure to antiepileptic drugs and dental agenesis. PLoS One. 2014; 9(1):e84420.

25. Dahllöf G, Rozell B, Forsberg CM, Borgström B. Histologic changes in dental morphology of high dose chemotherapy and total body irradiation. Oral Surg Oral Med Oral Pathol. 1994;77(1):56-60.

26. Billings RJ, Berkowitz RJ, Watson G. Teeth. Pediatrics. 2004; 113(4 Suppl):1120-1127.

27. Matalova E, Fleischmannova J, Sharpe PT, Tucker AS. Tooth agenesis: from molecular genetics to molecular dentistry. J Dent Res. 2008;87(7): $617-623$.

28. Guruprasad R, Nair PP, Hegde K, Singh M. Nonsyndromic Oligodontiaa case report. IJDA. 2011;3:450-453. Available from: http://www.nacd. in/ijda/volume-03-issue-01/106-non-syndromic-oligodontia. Accessed March 30, 2016

29. Duijf PG, van Bokhoven H, Brunner HG. Pathogenesis of splithand/split-foot malformation. Hum Mol Genet. 2003;12(Suppl 1): R51-R60.

30. Rüdiger RA, Haase W, Passarge E. Association of ectrodactyly, ectodermal dysplasia, and cleft lip-palate. Am J Dis Child. 1970;120(2): $160-163$.

31. van Bokhoven H, Hamel BC, Bamshad M, et al. p63 Gene mutations in eec syndrome, limb-mammary syndrome, and isolated split handsplit foot malformation suggest a genotype-phenotype correlation. Am J Hum Genet. 2001;69(3):481-492.

32. Huna-Baron R, Kupersmith MJ. Idiopathic intracranial hypertension in pregnancy. J Neurol. 2002;249(8):1078-1081.

33. Scott WJ Jr, Bell SM, Schreiner CM. The role of sodium hydrogen exchange in the teratogenic response to acetazolamide. Congenital Anomalies. 2001;41(1):76-82.

34. Storch TG, Layton WM Jr. The role of hypercapnia in acetazolamide teratogenesis. Experientia. 1971;27(5):34-535.

35. Weaver TE, Scott WJ Jr. Acetazolamide teratogenesis: interaction of maternal metabolic and respiratory acidosis in the induction of ectrodactyly in C57BW6J mice. Teratology. 1984;30(2):195-202.

36. Meadows M. Pregnancy and the drug dilemma. FDA Consum. 2001; 35(3): $16-20$

37. Worsham F Jr, Beckman EN, Mitchell EH. Sacrococcygeal teratoma in a neonate. Association with maternal use of acetazolamide. JAMA. 1970;240(3):251-252.

38. Merlob P, Litwin A, Mor N. Possible association between acetazolamide administration during pregnancy and metabolic disorders in the newborn. Eur J Obstet Gynecol Reprod Biol. 1990;35(1):85-88. 


\section{Publish your work in this journal}

Drug Design, Development and Therapy is an international, peerreviewed open-access journal that spans the spectrum of drug design and development through to clinical applications. Clinical outcomes, patient safety, and programs for the development and effective, safe, and sustained use of medicines are a feature of the journal, which

has also been accepted for indexing on PubMed Central. The manuscript management system is completely online and includes a very quick and fair peer-review system, which is all easy to use. Visit http://www.dovepress.com/testimonials.php to read real quotes from published authors.

Submit your manuscript here: http://www.dovepress.com/drug-design-development-and-therapy-journal 